\title{
Experimental Supratrigonal Cystectomy. Evaluation of Long-Term Complications
}

\author{
Milton Barros, Reinaldo Martinelli, Heonir Rocha
}

Section of Urology (MB) and Nephrology (RM, HR), School of Medicine, Federal University of Bahia, Salvador, Bahia, Brazil

\begin{abstract}
Objective: The present study aims at assessing the occurrence of pyelonephritis and long-term complications in rats submitted to surgical reduction of bladder capacity.

Materials and Methods: Sprague-Dawley rats were submitted to supratrigonal cystectomy (29 animals) or sham operation (15 animals) and sacrificed 2, 4 and 6 months after the surgical procedure. The arterial blood pressure and serum creatinine levels were assessed before the surgery and at the time of the sacrifice. After the sacrifice a careful inspection of the urinary apparatus was performed to the characterization of the hydronephrosis and for the detection of the presence of calculi. With sterile technique, the urine was aspirated from the bladder and the kidneys removed and sent to a microbiologic study.

Results: Pyelonephritis was frequent in animals submitted to supratrigonal cystectomy. The most frequent and isolated microorganisms were Staphylococcus sp. and E. coli. The presence of urinary calculi was correlated significantly to the presence of urinary tract infection $(\mathrm{p}<0.003)$. Arterial hypertension was frequent amongst animals submitted to supratrigonal cystectomy. Serum creatinine was high in $72.4 \%$ of the animals in the group submitted to supratrigonal cystectomy. The presence of calculi and pyelonephritis were frequent in rats presenting renal insufficiency and in hypertensive rats.

Conclusions: The long-term course of urinary infection in rats submitted to supratrigonal cystectomy was characterized by a high incidence of renal insufficiency and arterial hypertension that seem to be related to dysfunction and bladder obstruction induced by an extensive surgical procedure and the presence of urolithiasis and pyelonephritis.
\end{abstract}

Key words: pyelonephritis; experiments; rats; cystectomy; lithiasis

Int Braz J Urol. 2006; 32: 350-4

\section{INTRODUCTION}

Urinary infection is one of the most frequently found bacterial infections in medical practice. Clinical forms are variable, ranging from asymptomatic bacteriuria to pyelonephritis and sepsis, depending on the degree of the disease $(1,2)$. Both factors related to the virulence of the infecting agent and the factors of host defense (natural, immunologic and molecular), are determinant of the severity of the urinary infection (3-6).
The intact bladder has important mechanisms of protection against bacterial infections (7-9). It is widely known that bladder dysfunction related to structural alterations or to neurological diseases cause urinary tract functional obstruction, stasis and vesicoureteral reflux, increasing the incidence of urinary tract infections $(7,10-12)$. The role of the bladder capacity as a protection/increase factor to the predisposition to urinary infection and pyelonephritis, is not completely understood. In previous experimental studies the increase of urinary infection and spon- 
taneous pyelonephritis was observed in rats submitted to different types of cystectomies when studied in the first postoperative weeks (13).

The objective of the present study was to evaluate the occurrence of long-term urinary tract infection and other complications in rats submitted to surgical reduction of the bladder capacity.

\section{MATERIALS AND METHODS}

Sprague-Dawley rats approximately 2 months old were anesthetized with pentobarbital and submitted to supratrigonal cystectomy, leaving both ureters intact. A second group of rats were submitted to a sham surgery in which, though a suprapubic incision, the bladder was exposed and left intact. All surgical procedures were aseptic. During all study regular rat food and filtered water ad libitum were provided. Groups of animals were sacrificed 2, 4 and 6 months after the surgical procedure. Arterial blood pressure and serum creatinine level were measured before the surgical procedure and at the time of the sacrifice.

After the sacrifice a careful inspection of the urinary tract was performed to characterize hydronephrosis, defined by the presence of dilation of the renal pelvis and the ureters and to detect the presence of calculi. Afterwards, bladder urine was aspirated and sent to microbiologic analyses. The kidneys were then removed and sectioned. Half of the kidney was homogenized in a $5 \mathrm{~mL}$ sterile saline solution (TRI-instruments) and after successive dilutions $\left(10^{-1}, 10^{3}, 10^{-5}\right)$ slides to determine the number of bacteria were made after the correction to the dilution factor. Microbiological standard techniques were used. The finding of $\geq 10^{5}$ units forming colonies $\mathrm{ufc} / \mathrm{mL}$ of urine indicated the presence of infection. We considered pyelonephritis the presence of $\geq 10^{5}$ ufc per gram or renal tissue $(13,14)$. Animals with systolic arterial blood pressure persistently superior to $140 \mathrm{mmHg}$ were considered hypertensive. Renal insufficiency was defined by serum creatinine superior to $1.0 \mathrm{mg} / \mathrm{dL}$.

Data are presented as mean \pm standard deviation. Student's t test was used to compare continuous variables among groups and the $\chi^{2}$ test and Fisher exact test for categorical variables as appropriate. $\mathrm{P}<0.05$ was considered as statistically significant.

\section{RESULTS}

Eighty seven rats were submitted to supratrigonal cystectomy and 20 rats were submitted to sham surgery. The mean systolic arterial pressures measured at the animals' tails before the surgeries was $103.3 \pm 11.6 \mathrm{mmHg}(103.6 \pm 12.7 \mathrm{mmHg}$ for animals submitted to supratrigonal cystectomy and $102.0 \pm$ $9.4 \mathrm{mmHg}$ for the animals in the sham group, $\mathrm{p}>$ 0.05 ) and mean serum creatinine was $0.74 \pm 0.24 \mathrm{mg} /$ $\mathrm{dL}(0.77 \pm 0.23 \mathrm{mg} / \mathrm{dL}$ and $0.66 \pm 0.24 \mathrm{mg} / \mathrm{dL}$ respectively to the groups submitted to supratrigonal cystectomy and sham, $\mathrm{p}>0.05)$. From the surviving animals submitted to supratrigonal cystectomy, 10 were studied 2 months after surgery, 9 were studied 4 months after surgery and 10 animals were studied 6 months after the surgical procedure. The incidence of pyelonephritis, the frequency of lithiasis and the number of animals with serum creatinine increase (renal insufficiency) and of the systolic pressure are shown in Table-1.

Pyelonephritis was frequent in animals submitted to supratrigonal cystectomy, present in 50\% of the animals in the first 2 months follow-up, in $67 \%$ in the fourth month and in $60 \%$ in the sixth month. In every one of these animals urine culture was also positive for the same bacteria. From the total of 17 animals with pyelonephritis, Staphylococcus sp were isolated in 8 (47\%), E. coli in $6(35.3 \%)$. Proteus sp. in one. In one rat sacrificed 2 months after the cystectomy Staphylococcus sp. + E. coli + Klebsiella sp. were isolated $(5.9 \%)$ and in another rat sacrificed 6 months after the surgical procedure Staphylococcus sp. + E. coli were isolated (5.9\%).

The presence of vesical calculi (Table-1) was elevated (62\%) and was significantly correlated to the presence of urinary tract infection $(\mathrm{p}<0.003)$. Arterial hypertension was also frequent amongst animals submitted to supratrigonal cystectomy, opposite to what was observed in the sham group.

At the time of the sacrifice, mean serum creatinine was more elevated in the group of animals sub- 
Table 1 - Complications in rats submitted to supratrigonal cystectomy and sham surgery.

\begin{tabular}{lrcccc}
\hline & N & PN / UTI & Urinary Calculus & Renal Insufficiency & Arterial Hypertension \\
\hline Cystectomy & & & & & \\
2 months & 10 & 5 & 5 & 10 & 4 \\
4 months & 9 & 6 & 8 & 6 & 5 \\
6 months & 10 & 6 & 5 & 5 & 0 \\
Sham & & 0 & 0 & 0 & 0 \\
2 months & 6 & 0 & 0 & 1 & 0 \\
4 month & 4 & 0 & 0 & 0 & \\
6 months & 5 & & & \\
\hline
\end{tabular}

PN = pyelonephritis; $U T I=$ urinary tract infection.

mitted to supratrigonal cystectomy in relation to the group submitted to sham surgery $(1.34 \pm 0.64$ versus $0.75 \pm 0.20$, respectively, $\mathrm{p}<0.003$ ). Serum creatinine was at normal levels in all 15 rats submitted to sham surgery, however it was high in $21(72.4 \%)$ of the 29 rats submitted to supratrigonal surgery $(\mathrm{p}<$ 0.0006).

There was a statistically significant association ( $\mathrm{p}<0.001)$ between the presence of calculi and pyelonephritis - $83 \%$ of the animals with urinary calculus had associated pyelonephritis (Table-2). The presence of renal insufficiency $(72.2 \%)$ and of arterial hypertension $(50 \%)$ were frequent in animals with urinary calculus as well as in rats with pyelonephritis $(76.5 \%$ and $64.7 \%$, respectively) even though not statistically significant. Similarly, the presence of urinary calculus and pyelonephritis were frequent in rats presenting renal insufficiency $(61.9 \%$ each) and in hypertensive rats $(69.2 \%$ and $84.5 \%$, respectively).

\section{COMMENTS}

The long-term course of urinary tract infection in rats submitted to supratrigonal cystectomy was complicated by the high incidence of renal insufficiency and arterial hypertension. In a previous study in animals assessed 4 weeks after the same surgical procedure used in the present study, an increased frequency of pyelonephritis/urinary infection and calculi was demonstrated. We have concluded that the infection is spontaneous and related to an accentuated vesical dysfunction induced by the surgical procedure, with the section of muscle fibers and nerves, causing functional obstruction, urinary stasis and vesicoureteral reflux (13).

It is possible that the accentuated reduction of bladder capacity and consequent reduction of its complacency, increasing intraluminal pressure, leads to hydronephrosis urinary stasis, predisposing to urinary infection, pyelonephritis and renal parenchyma

Table 2 - Association between renal insufficiency and arterial hypertension in rats with urinary calculus and pyelonephritis.

\begin{tabular}{lccccc}
\hline & N & Urinary Calculus & PN / UTI & Arterial Hypertension & Renal Insufficiency \\
\hline Urinary calculus & 18 & & 15 & 9 & \\
Pyelonephritis / UTI & 17 & 15 & & 11 & 13 \\
Hypertension & 13 & 9 & 11 & & 13 \\
Renal insufficiency & 21 & 13 & 13 & 9 & 9 \\
\hline
\end{tabular}

$P N=$ pyelonephritis; $U T I=$ urinary tract infection . 
lesion (7,10,15-17). Additionally, the association between the urinary infection and the formation of calculi suggests that the presence of urolithiasis keeps the infection and increases the possibility of vesicoureteral reflux and renal damage $(11,17)$. The infecting flora in the present study, similarly to previous studies, called the attention to the frequency of gram-positive bacteria. The infection did not seem to be related to the contamination during the surgical act, since strict aseptic techniques were used, even though this possibility cannot be secluded.

The high frequency of arterial hypertension and/or renal insufficiency in the present investigation was not unexpected, even though they were not analyzed in shot-term studies (13). The trend of being kept constant during the period of the study suggest that they are complications installed precociously. However, the constancy observed can be due to a selection bias, since 41 of the 81 rats submitted to supratrigonal cystectomy died in the first 4 months follow-up suggesting that severely affected animals did not survive until the sacrifice period.

The presence of vesical calculus was documented in $62 \%$ of the rats submitted to supratrigonal cystectomy and was significantly correlated to the presence of urinary infection. Hydronephrosis was also frequently observed to sacrifice, even though the present study did not aim to study the incidence of obstructive uropathy. The association of lithiasis and pyelonephritis was high in animals with renal insufficiency (61.9\%). Pyelonephritis associated to obstruction of the urinary tract is an important cause of renal parenchyma lesion and subsequent renal insufficiency and arterial hypertension $(15,16,18,19)$. Additionally, $69.2 \%$ of hypertensive animals has, associated renal insufficiency, being arterial hypertension an important cause for and factor of progression of renal insufficiency (20).

\section{CONCLUSIONS}

The incidence of urinary infection/pyelonephritis and urolithiasis is high in rats submitted to supratrigonal cystectomy. The long-term course was characterized by an elevated incidence of renal in- sufficiency and arterial hypertension, which seem to be related to vesical dysfunction induced by the extensive surgical procedure and the presence of urolithiasis and pyelonephritis with extensive destruction of the renal parenchyma.

\section{CONFLICT OF INTEREST}

None declared.

\section{REFERENCES}

1. Kucheria R, Dasgupta P, Sacks SH, Khan MS, Sheerin NS: Urinary tract infections: new insights into a common problem. Postgrad Med J. 2005; 81: 83-6.

2. Kunin CM: Urinary Tract Infection. Detection, Prevention and Management. 5th ed., Baltimore, Williams \& Wilkins. 1997.

3. Roberts JA: Etiology and pathophysiology of pyelonephritis. Am J Kidney Dis. 1991; 17: 1-9.

4. Svanborg C, Godaly G: Bacterial virulence in urinary tract infection. Infect Dis Clin North Am. 1997; 11: 513-29.

5. Sobel JD: Pathogenesis of urinary tract infection. Role of host defenses. Infect Dis Clin North Am. 1997; 11: 531-49.

6. Zhang D, Zhang G, Hayden MS, Greenblatt MB, Bussey C, Flavell RA, et al.: A toll-like receptor that prevents infection by uropathogenic bacteria. Science. 2004; 303: 1522-6.

7. Lloyd-Davies RW, Hinman Jr. F. Structural and functional changes leading to impaired bacterial elimination after overdistention of the rabbit bladder. Invest Urol. 1971; 9: 136-142.

8. Parsons CL, Greenspan C, Mulholland SG: The primary antibacterial defense mechanism of the bladder. Invest Urol. 1975; 13: 72-8.

9. Mulholland SG: Lower urinary tract antibacterial defense mechanisms. Invest Urol. 1979; 17: 93-7.

10. Lapides J: Role of Hydrostatic Pressure and Distention in Urinary Tract Infection. In: Kass EH (ed.), Progress in Pyelonephritis. Philadelphia, Davis. 1965.

11. Risdon RA, Godley ML, Parkhouse HF, Gordon I, Ransley PG: Renal pathology and the 99mTc-DMSA image during the evolution of the early pyelonephritic scar: an experimental study. J Urol. 1994; 151: 767-73.

12. Hodson CJ, Maling TM, McManamon PJ, Lewis MG: The pathogenesis of reflux nephropathy (chronic atro- 


\section{Experimental Supratrigonal Cystectomy}

phic pyelonephritis). Br J Radiol. 1975; Suppl 13: 126.

13. Rocha H, Barros M: Experimental pyelonephritis: characteristics of infection in rats following reduction of bladder capacity. Proc Soc Exp Biol Med. 1965; 120: 122-4.

14. Poljakovic M, Persson K: Urinary tract infection in iNOS-deficient mice with focus on bacterial sensitivity to nitric oxide. Am J Physiol Renal Physiol. 2003; 284: F22-31.

15. Lomberg H, de Man P, Svanborg Eden C: Bacterial and host determinants of renal scarring. APMIS. 1989; 97: 193-9.

16. Johnson DE, Russell RG, Lockatell CV, Zulty JC, Warren JW: Urethral obstruction of 6 hours or less causes bacteriuria, bacteremia, and pyelonephritis in mice challenged with "nonuropathogenic" Escherichia coli. Infect Immun. 1993; 61: 3422-8.

17. Adam RM: Recent insights into the cell biology of bladder smooth muscle. Nephron Exp Nephrol. 2006; 102: e1-7.

18. Hannerz L, Celsi G, Eklof AC, Olling S, Wikstad I, Aperia A: Ascending pyelonephritis in young rats retards kidney growth. Kidney Int. 1989; 35: 11337.

19. Klahr S, Morrissey J: Obstructive nephropathy and renal fibrosis. Am J Physiol Renal Physiol. 2002; 283: F861-75.

20. Bakris GL: Hypertension and nephropathy. Am J Med. 2003; 115 Suppl 8A: 49S-54S.

Accepted after revision:

April 3, 2006

\section{Correspondence address:}

Dr. Milton Barros

Hosp Univ Prof. Edgard Santos, 6/Lab 1117

Rua João das Botas S/N

Salvador, Bahia, 40110-160, Brazil

Fax: + $55713235-8854$

E-mail:nefro@ufba.br 